\title{
The Effect of Age and Position on Favor Asking
}

\author{
Rana Mohammed Alshehri \\ Department of Applied Linguistics \\ Royal Commission College and Institutes \\ Yanbu University College \\ Yanbu, Kingdom of Saudi Arabia \\ E-mail: ranaalshehri00@gmail.com
}

Received: November 9, 2019 Accepted: January 25, 2020 Published: February 1, 2020

doi:10.5296/elr.v6i1.16369

URL: https://doi.org/10.5296/elr.v6i1.16369

\begin{abstract}
This study investigated the speech act of asking for a favor in Saudi Arabia. The aim of this study was to investigate the effect of age and position in a favor asking etiquette. The researcher used a qualitative method to collect the data. The participants of this research were 51 female and 53 male high school students who were native speakers of Arabic in Saudi Arabia. The research tool was a questionnaire which was used to get the participants' reaction about a favor asking. This research was meant to find significant information about favor asking etiquette in KSA for males and females. The results showed that Saudi females and males are polite and indirect when they ask for a favor from their elders. The results also showed that most Saudi females and some of the Saudi males prefer to be indirect while asking a favor from their peers. Based on the results, a set of recommendations were made.
\end{abstract}

Keywords: Favor asking, Saudi Arabia, Etiquette, Speech act

\section{Introduction}

This study investigates how the politeness of Saudi Arabic high school student effect by age and position when they ask for a favor. Affective communication is a result of knowing how to say something in a particular way without embarrassing or humiliating yourself and the other interlocutor (Brown \& Levinson, 1987). According to Paltridge (2012), politeness choices are not universal and could be culture-specific and language-specific. He further stated that what may be polite in one culture may not be considered the same way in another.

In general, a study on Arabic speech acts, specifically related to favor-asking, is needed because few studies have been conducted in Saudi Arabia. This research was important as it 
explained preferred ways of favor asking based on age, gender, and status in Saudi Arabia. This study may also result in further studies on similar topics.

\subsection{Purpose of the Study}

The purpose of this study was to find the linguistic and social distribution of favor asking in Saudi Arabia and to fill those gaps in the literature and to learn which way was used more, direct or indirect.

\subsection{Research Questions}

This study attempted to answer the following question:

How do Saudi male and female high school students ask for favors from people depending on their age and/or position?

\section{Relevant Previous Studies}

Many researchers have conducted their studies to investigate favor asking in different languages.

Alrefai (2012) conducted a study to investigate the effect of distance and social power on both core strategies and modifications of favor asking in Kuwaiti Arabic. The study was conducted in the U.S. The participants were 30 male native speakers of Kuwaiti Arabic studying at U.S. universities. They were randomly selected from a list the Kuwaiti Embassy in Washington, D.C. provided. The participants' ages were from 19 to 40 years old, who had not spent more than three years in the U.S. The research methodology was quantitative. The researcher used a written discourse completion test (DCT) to collect the data. The participants received the test via email also, were inquired as to whether they would take an interest in the research. The email contained an agreement form, a survey, and DCT. Recipients were requested to complete the agreement form, survey, and DCT. The option of writing down their replies or attaching a scanned or digital copy was given to the participants. The results showed that social power significantly affected strategy use while distance did not.

Alrefaee and Alghamdi (2019) conducted a study to investigate refusals among Yemeni EFL learners. This study was significant as it tries to find out the influence of linguistic proficiency on the negative pragmatic transfer. The study concluded that Yemeni EFL learners of high and Low proficiency level were influenced by the mother language when interacting in L2. The paper confirms the importance of teaching pragmatic competence for Arab learners.

Another study was conducted by Alqahtani (2015) to examine the influence of social distance, degree of imposition, and power on favor asking, in terms of both core strategy and modification. The participants were 60 female college students who were native speakers of Saudi Arabic. Also, favor asking in Saudi Arabic, Kuwaiti Arabic, and American English were compared and contrasted. The research methodology was quantitative. The researcher used a written discourse completion test (DCT) to collect the data. The researcher design a requested survey that contained 12 situations of favor asking that changed in the level of 
power, social distance, and the degree of imposition. The results showed that favor asking in Saudi Arabic was mostly direct and conventionally indirect. Some of the participants liked to used direct strategies where the others strongly disliked nonconventional. Favor asking in American English was found to be more different than favor asking in Saudi and Kuwaiti Arabic. The degree of imposition and social power had an influence on favor asking in Saudi Arabic where social distance did not.

Lee, Park, Imai, and Dolan (2012) conducted a series of studies on cultural differences between Japanese and Americans in the use of apologies and thanks in favor- asking e-mail messages. The studies were conducted in Japan and the United States. Three questionnaires were formed in both English and Japanese. The participants of the study used their mother tongue to complete the questionnaire. Each study is summarized below.

A study on cultural differences between Japanese and Americans in the use of apologies and thanks in favor- asking e-mail messages conducted by Lee, Park, Imai, and Dolan (2012). The participants were 74 Japanese males from a large university in Japan and 78 American males from one large Midwestern university in the United States. The participants' average age was 20 . The research methodology was quantitative. The researcher used a questionnaire to collect data. The participants were asked to request an e-mail with a favor for a particular situation. The results of the study showed that the Japanese prefer apologies to thanks, while the Americans seemed to prefer thanks to apologies.

Park, Lee, Imai, and Dolan (2012) also conducted a study to examine whether or not expressing apologies or thanks along with favor asking was used to reduce the face threats made by favor asking. The participants were all male. The Americans were 322 students from a large Midwestern university in the United States and 312 Japanese students from a large university in Japan. The participants' average age was 20. The research methodology was quantitative. The participants were asked to complete one of four versions of a questionnaire designed to assess their perceptions of face threats associated with favor asking. The researchers used a paper-and-pencil survey that used 2 cultures: the United States and Japan and 4 speech act: control, apology, gratitude, and apology and gratitude. The results of the study showed that Japanese repeated their apologies to reduce the perceptions of face threats; whereas, Americans repeated their thanks.

Another study was conducted by Imai, Park, Lee, and Dolan (2012) to examine if repeated expressing apologies, thanks, and both along with favor asking was used to reduce the face threats made by favor asking. The research methodology was quantitative. The participants were 200 American males from several universities in the United States and 217 Japanese male university students. The Japanese average age was 21 and the Americans' average age was 23. The participants were asked to write an e-mail with a favor for a particular situation to a singular person. The results of the study showed cultural differences between the Japanese and Americans. The Japanese repeated their apologies, whereas Americans repeated their thanks. Also, repeated thanks or both did not reduce the face threats associated with favor asking for either culture.

Another study was conducted by Imai, Park, Lee, and Dolan (2012) to examine if repeated 


\section{Macrothink

expressing apologies, thanks, and both along with favor asking was used to reduce the face threats made by favor asking. The research methodology was quantitative. The participants were 200 American males from several universities in the United States and 217 Japanese male university students. The Japanese average age was 21 and the Americans' average age was 23. The participants were asked to write an e-mail with a favor for a particular situation to a singular person. The results of the study showed cultural differences between the Japanese and Americans. The Japanese repeated their apologies, whereas Americans repeated their thanks. Also, repeated thanks or both did not reduce the face threats associated with favor asking for either culture.

Most of the studies were conducted to show the effect of social power and distance on favor asking. Few studies investigated the influence of social distance, degree of imposition and social power. This study is different from the previous studies in the way that it investigated the effect of age and position in a favor asking etiquette of Saudi male and female high school students.

\section{Method}

\subsection{Study Design}

The method of the study was quantitative which included a questionnaire to collect the data of the study. A questionnaire was distributed among the participants. It was designed to get the reaction of the participant about a given situation. The questionnaire contained 7 multiple choice questions, 5 related to favor -asking situations and 2 related to age and gender (see Appendix for the questionnaire).

\subsection{Participants}

The participants of this research were 104 students at high school in Saudi Arabia. The participants were 51 girls and 53 boys. Their ages were between 15 and 18 years of age.

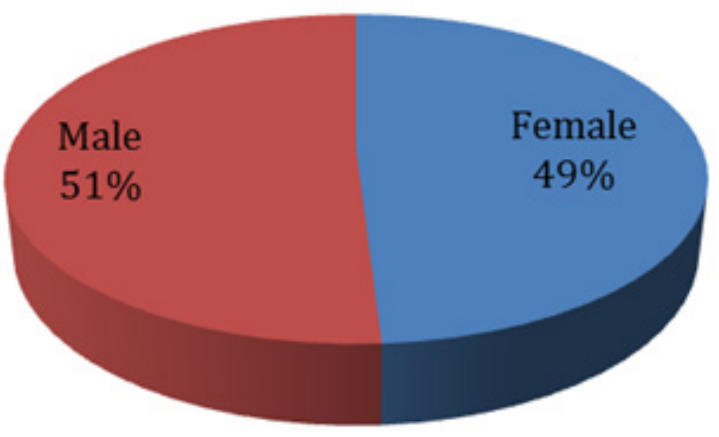

Figure 1. Distribution of participants gender 


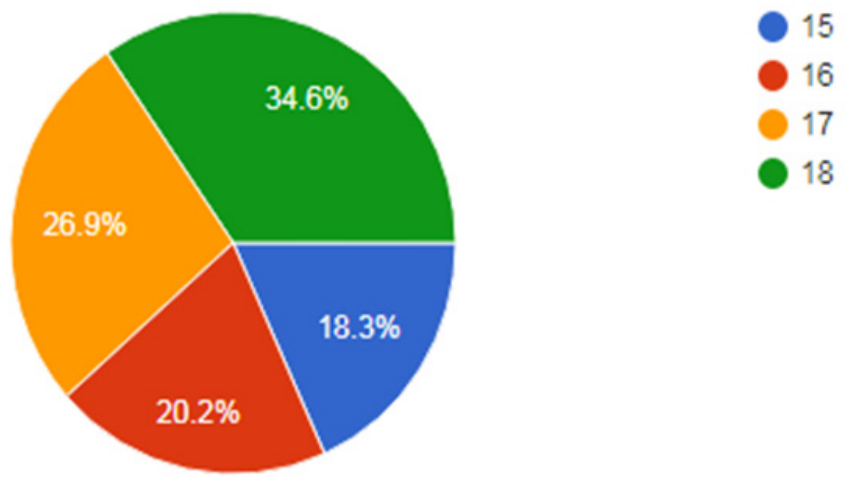

Figure 2. Distribution of participants age

\subsection{Instruments of Data Collection}

The study started by sending a WhatsApp message to 104 high school students and asked if they would agree to participate in the study. The purpose of the study was revealed to the participants in the same message. The message contained a link to an online questionnaire they were asked to complete if they agreed to be a participant of the study. Then, the results of the study were analyzed to determine whether there was any effect of gender, age or position on favor asking etiquette.

\subsection{Tools of Data Analysis}

The response of the participants was analyzed by Excel to answer the research question.

\section{Results and Discussion}

\subsection{Young Age and Low Position to Old Age and High Position}

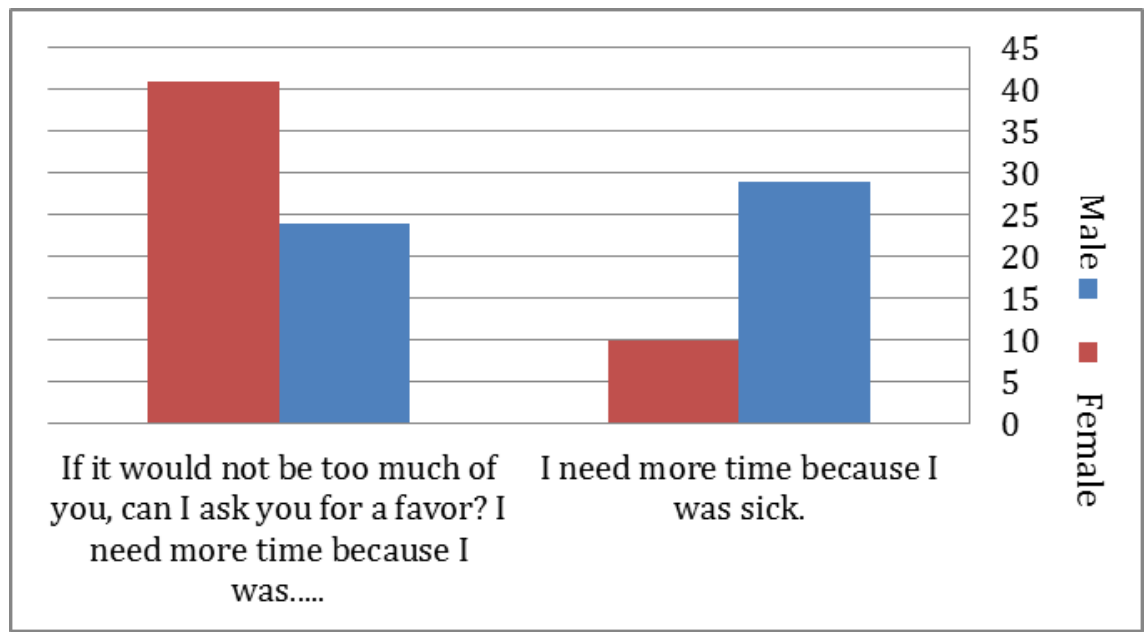

Figure 3. Female and male responses to Q3 


\section{Macrothink

The results of the third question showed that 41 females and 24 males chose "If it would not be too much of you, can I ask you for a favor? I need more time because I was...", 10 females and 29 males chose "I need more time because I was sick........".

It was clear that most of the females are indirect more than males when they were in needed situation with strong reason of their need while asking a favor from their teacher or elders. Females prefer to be indirect with older people such as their teacher even though they had the right to ask for the favor while males preferred to be more direct when they had the right to ask for the favor. So, the favor asking of females was affected by the age and position of the person they asked favors from while the favor asking of males did not. According to Alqahtani (2015)study results, females preferred to use conventional indirect while asking a favor from people who have a social power which was also clear in the current study. According to Alrefai (2012) study result, males preferred to use direct strategies over indirect. To sum up, Saudi women are more polite than Saudi males while asking for a favor.

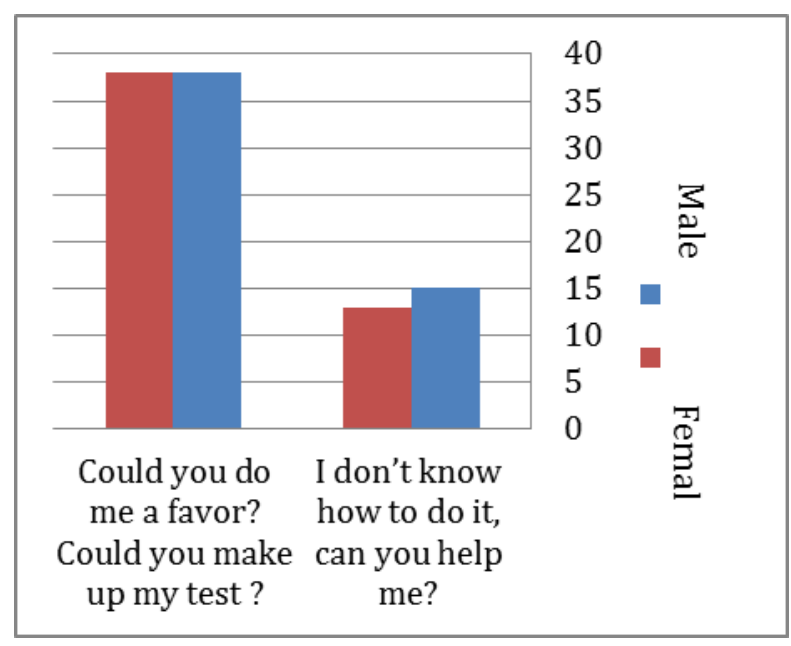

Figure 4. Female and male responses to Q4

The results for the fourth question showed 38 females and 38 males chose "could you do me a favor? Could you make up my test?", 13 females and 15 males chose "I don't know how to do it, can you help me?"

Both males and females were indirect when they were in a situation with low need while asking favors from their teacher or elders. In comparison to Q3 results, it is clear that females preferred to be indirect in both situations regardless of the reason while asking a favor while males prefer to be polite and indirect only in the favor asking situation with a weak reason. These results are consistent with the Alqahtani (2015)study which found that females preferred to use conventional indirect over direct strategies while asking favor at low power situation. The findings also support the findings of Alrefai (2012) which showed that males preferred to use indirect strategies more than direct at low power situation. Interestingly, females prefer to be indirect regardless of the need or reason while males only prefer being indirect when they do not have a strong reason. 


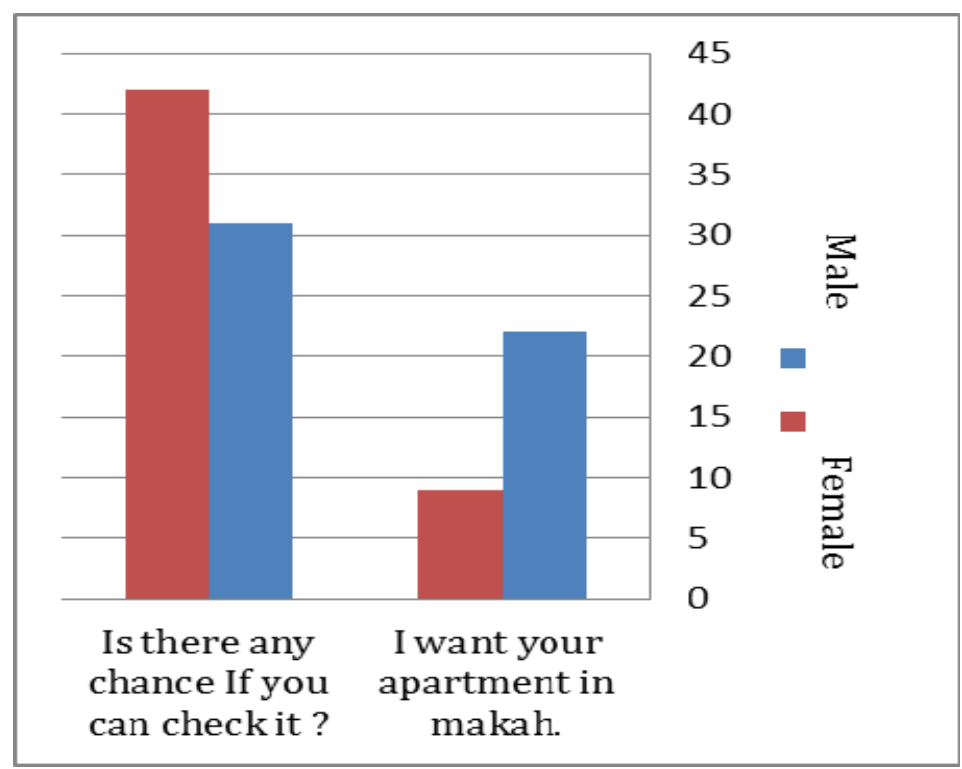

Figure 5. Female and male responses to Q 5

The results for the $5^{\text {th }}$ question showed that 42 females and 31 males chose "Is there any chance If you can check it", 9 females and 21 males chose" I want your apartment in Makah."

Most of the females and males were polite and indirect while asking a favor from their friend. There were some males and a few females who prefer to use the direct way with their friend.

There is no difference between females and males in asking a big favor from their friend such as using their friend's apartment that he or she will not use for this year and they are in real need of it. So both females and males prefer to be polite and indirect while asking a big favor from their friend even though they know he or she can do it for them. It is clear that in Saudi culture a person is expected to be indirect when asking for big favor, to be directly acceptable. This finding can be explained by Goldschmidt (1988) who pointed out using indirect ways to ask a very high or big favor gives the listener the feeling that it is not guaranteed that he or she would be able to comply with it. 


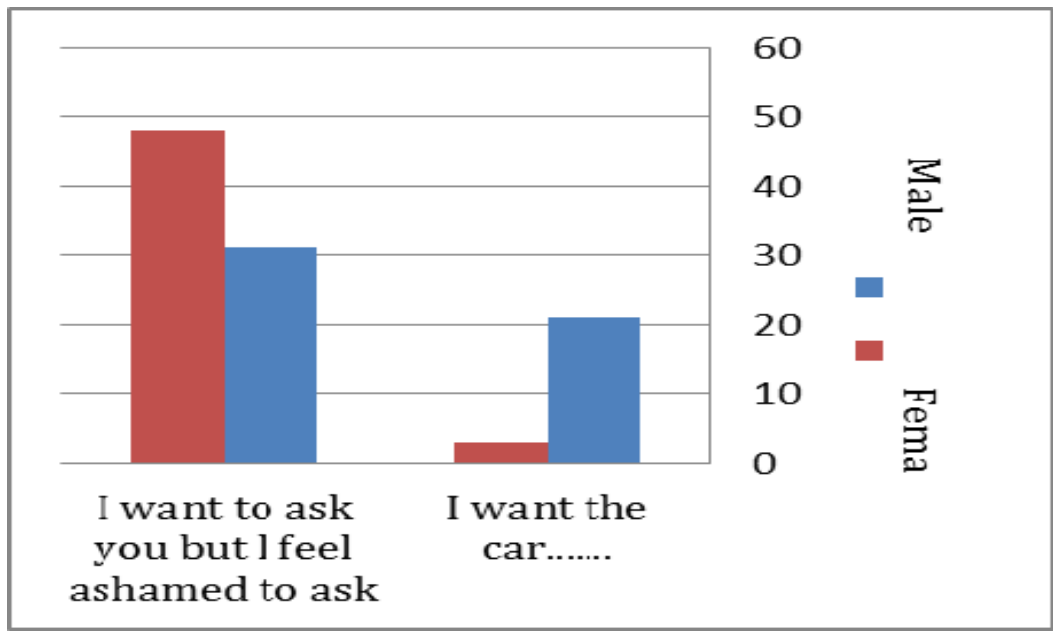

Figure 6. Female and Male responses to Q6

The results for the $6^{\text {th }}$ question showed that 48 females and 31 males chose "I want to ask you but $l$ feel ashamed to ask.", 3 females and 21 males chose " I want the car.......".

Most of the females and males prefer to show their friend they are very shy to ask for that favor when they did not really need help such as asking their friend to give them her or his new car only to hang out with friends. But a few females and some males prefer to be direct. This result is affected by the Saudi cultural background of what the Saudis call fazzah which means you have to help your people even though this help may cost you your life. So favor asking is really affected by not only the age it is also affected by the position and the need of the favor.

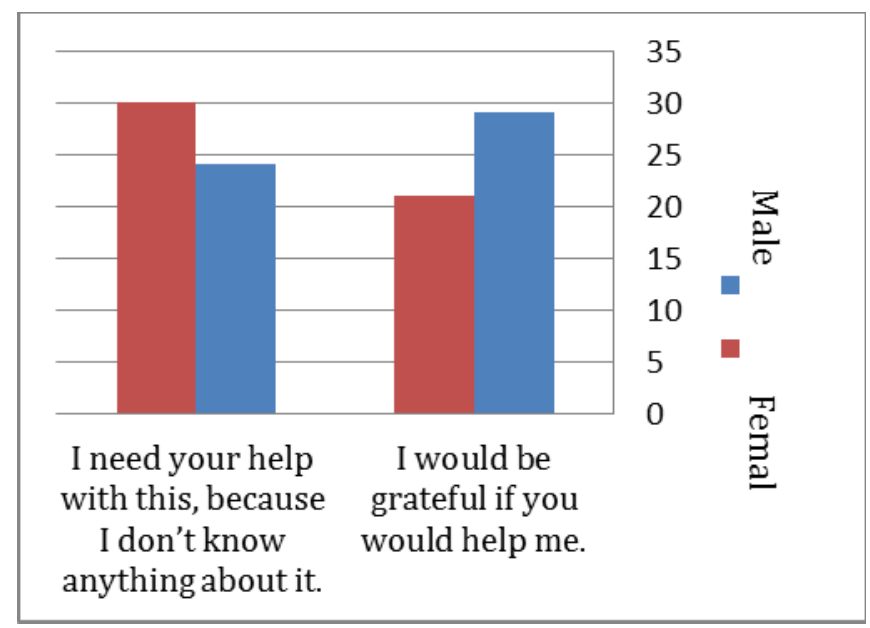

Figure 7. Female and male responses to Q7

The results for the $7^{\text {th }}$ question showed that 30 females and 24 males chose "I need your help with this, because I don't know anything about it.", 21 females and 29 males chose "I would be grateful if you would help me." 
Most of the females and some males prefer to be direct while asking a small favor from their friend when they were in a real need situation where the others prefer to be indirect. So as it is clear here females chose to be direct when asking a small favor from their friend. According to the study by Alrefai (2012), males strongly preferred to use indirect over direct when asking favors from others who have the same level of social power. And according to Alqahtani (2015) females prefer to use both direct and conventional indirect strategies while asking favors from people who are at the same level of power, but the result here showed the opposite. To sum up, males prefer to be polite when they ask for favors from people who are at the same level of power.

\section{Conclusion}

\subsection{Summary of Findings}

The purpose of the study was to find the linguistic and social distribution of favor asking in Saudi Arabia and to fill those gaps in the literature and to learn which way was used more, direct or indirect. The results showed that Saudi females and males are indirect when they ask for a favor from older people. Most of the Saudi females and some of the Saudi males are polite and prefer to be indirect while asking a favor from their peers. Also, Saudi females prefer to be direct when asking a small favor from their friend.

\subsection{Limitations of the Study}

The results of this study cannot be generalized due to the participants' number which was too small. It also did not cover all of Saudi Arabia city.

\subsection{Recommendations}

The researcher has a set of recommendations for future study. It is recommended for researchers to try to cover all Saudi Arabia cities and select a large number from each dialect. Also, it is recommended to use open-ended questions to get more honest responses.

\section{References}

Alqahtani, A. N. (2015). Favor asking in Saudi Arabic (Doctoral dissertation). Oklahoma State University, Stillwater.

Alrefaee, Y., \& Alghamdi, N. (2019). Refusals among Yemeni EFL Learners: A Study of Negativ Pragmatic Transfer and Its Relation to Proficiency. Asian EFL Journal, 25, 191-214.

Alrefai, E. (2012). Favor asking in Kuwaiti Arabic: Effects of power and distance on core strategies and modification. (Unpublished doctoral thesis). Oklahoma State University, Stillwater.

Brown, P., \& Levinson, S. C. (1987). Politeness: Some universals in language usage. Cambridge University Press. https://doi.org/10.1017/CBO9780511813085

Geertz, C. (1960). The Religion of Java. Glencoe. Ill: The Free Press of Glencoe.

Goldschmidt, M. M. (1998). Do me a favor: A descriptive analysis of favor asking sequences in American English. Journal of Pragmatics, 29(2), 129-153. https://doi.org/10.1016/S0378 $-2166(97) 00038-6$ 


\section{Macrothink}

Imai, T., Lee, H. E., Park, H. S., \& Dolan, D. (2012). Whether or not expressing apologies or thanks along with favor asking used to reduce the face threats made by favor asking. Journal of Language and Social Psychology, 31(3), 263-289.

Lee, H. E., Park, H. S., Imai, T., \& Dolan, D. (2012). Cultural differences between Japan and the United States in uses of "apology" and "thank you" in favor -asking messages. Journal of Language and Social Psychology, 31(3), 263-289. https://doi.org/10.1177/0261927X 12446595

Paltridge, B. (2012). Discourse analysis: An introduction. Bloomsbury Publishing.

Park, H. S., Lee, H. E., Imai, T., \& Dolan, D. (2012). Repeating apologies, thanks, and both along with favor asking used to reduce the face threats made by favor asking. Journal of Language and Social Psychology, 31(3), 263-289.

\section{Appendix}

Appendix 1. Questionnaire

اعز ائي الطلاب والطالبات اشكركم لمشاركتكم في هذا الاستبيان. الهدف من هذه الدراسة هو إلقاء الضوء الطاء على أساليب

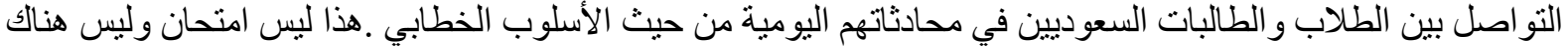

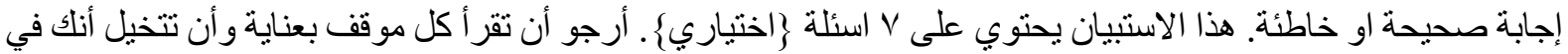

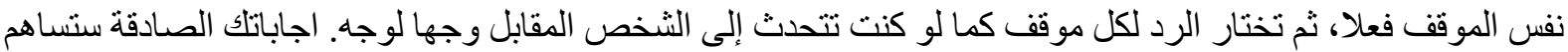

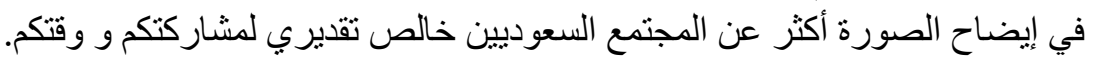

Dear student thank you for participating in this survey. The purpose of this study is to shed light on the way of communication between Saudi students in their daily conversations on the way of favor asking. This is not an exam and there is no right or wrong answer. This survey contains 7 multiple choice questions. Please read each position carefully and imagine that you are actually in the same position, and then choose to respond to each position as if you were talking to the opposite person face to face. Your sincere answers will help to clarify the picture more about the Saudi community. I sincerely appreciate your participation and your time.

\begin{tabular}{|c|c|}
\hline Q1)What is your gender? Male/female & س1) ما هو جنسك؟ ذكر/انثى \\
\hline Q2)What is your age? $15 / 16 / 17 / 18$ & س2) كم عمرك؟ 18/17/16/15 \\
\hline $\begin{array}{l}\text { Q3) You have only } 2 \text { hours left to submit } \\
\text { your homework which you couldn't finish } \\
\text { because you were sick. What are you } \\
\text { going to say to your teacher? } \\
\text { A)If it would not be too much of you, can } \\
\text { I ask you for a favor? I need more time } \\
\text { because I was.........(Abee athlub mink } \\
\text { tholab ethaa maa alayk amr) } \\
\text { B) I need more time because I was sick. }\end{array}$ & 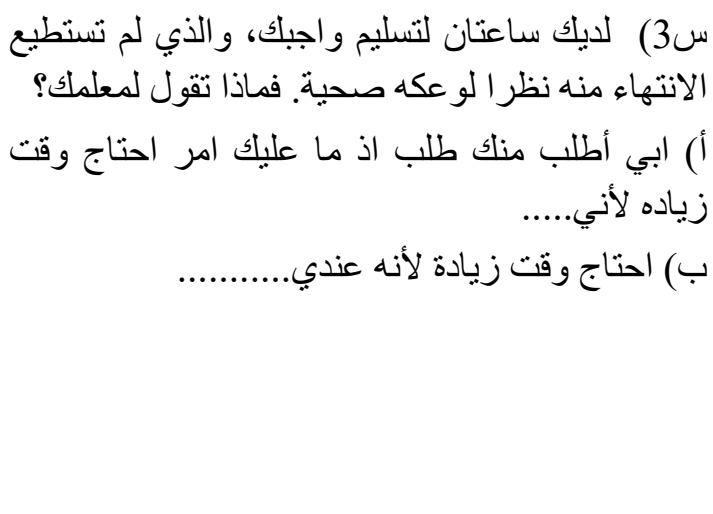 \\
\hline Q4) You want your teacher to make up & س4) تريد أن تطلب من أستاذك بأن يعيد الامتحان لك، \\
\hline
\end{tabular}


your test because you didn't do well in the test. What are you going to say? A)could you do me a favor? Could you make up my test ?...(ethaa maa alayk amr, mumkin thoead.......)

B) I don't know how to do it, can you help me? (maa arafth shlon, mumkin thosaa'edhnee)

Q5) You know that your friend who has an apartment in Makah does not go to need it this year, and you want to ask him to use it. What are you going to say?

A) Is there any chance If you can check it ......(fee majaal thashoof lee )

B) I want your apartment in makah .

Q6) You want to ask your friend to give you his new car so you can hen gout with your friends. What are you going to say?

A) I want to ask you but 1 feel ashamed to ask. ( abee athlub mink bas musthahee)

B) I want the car.......

Q7) You want your friend to help you with your project for a course. What are you going to say?

A) I need your help with this, because I don't know anything about it. (Abee mosaa'adhathak bil mawdhoo li anna maa endhee fikra anhu.)

B) I would be grateful if you would help me. (Yaa layth law thagdhar thosaa'edhnee)

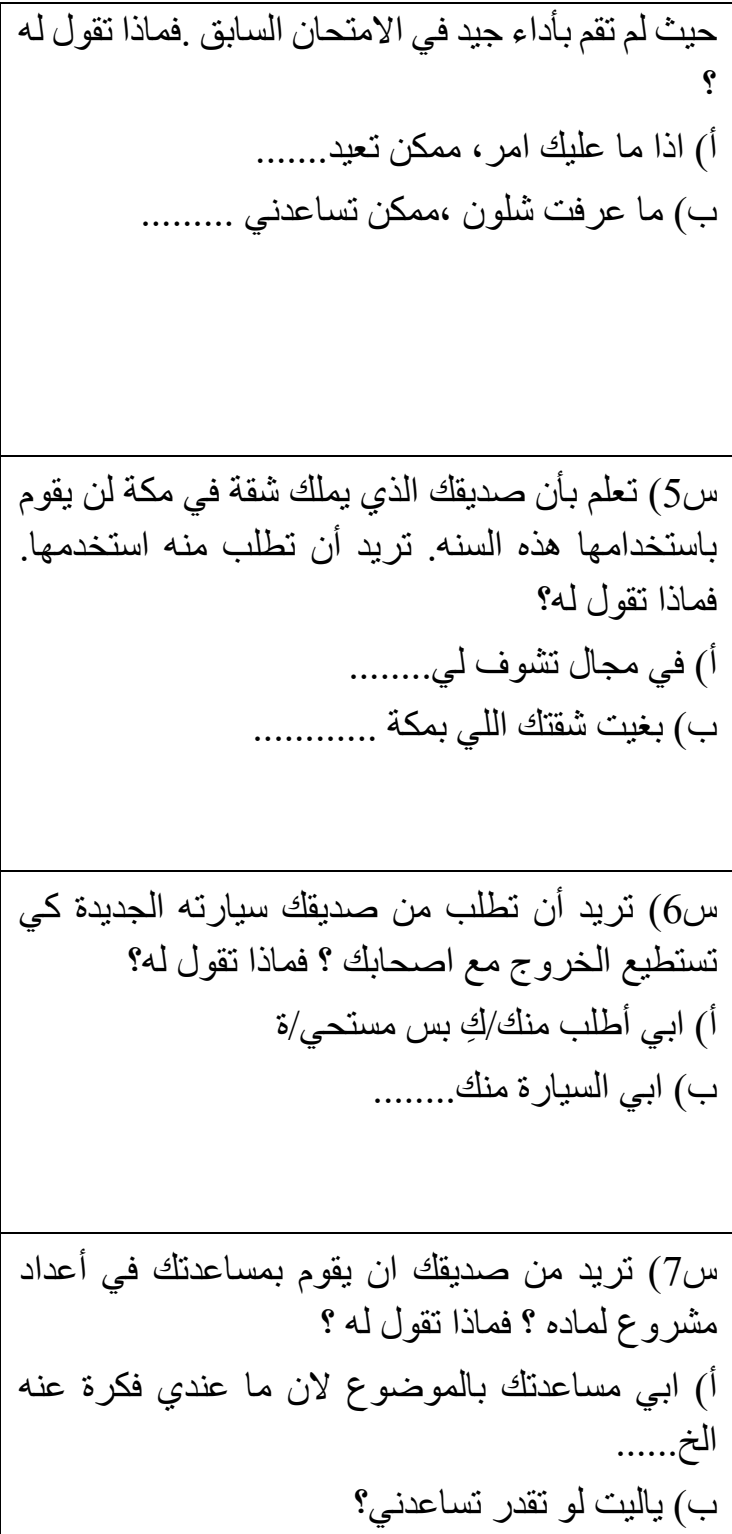

\section{Copyright Disclaimer}

Copyright reserved by the author(s).

This article is an open-access article distributed under the terms and conditions of the Creative Commons Attribution license (http://creativecommons.org/licenses/by/3.0/). 